\title{
A Vida do Espírito
}

\section{Márcia Zebina Araújo da Silva (UFG)}

E-mail:marcia@fchf.ufg.br

Resumo: Hegel não destina qualquer parte de suas obras para tratar da vida do espírito, porém, ao explicar os termos em que a vida deve ser compreendida na Ciência da Lógica, ele diferencia a dimensão especulativa da dimensão natural e espiritual, referindo-se, especificamente, à vida do espírito. Pretendemos, tão somente, mostrar a origem e as implicações deste conceito em Hegel, posto que, se a vida natural é o ponto mais alto a que chega a natureza, a vida espiritual é o destino do homem e o terreno próprio do desenvolvimento da liberdade.

Palavras-chave: vida, espírito, ontologia, lógica, idéia.

\section{A Ontologia da Vida}

Para explicitarmos a vida do espírito, no contexto da $\mathrm{Ci}$ ência da Lógica, devemos começar pelo esclarecimento do conceito de vida lógica para, assim, evidenciarmos a gênese lógica do espírito a partir da vida. Com efeito, Hegel não destina nenhum capítulo de sua obra para falar da vida do espírito, no entanto, ao explicitar os termos com os quais a vida deve ser compreendida na Ciência da Lógica, ele diferencia a vida lógica do espírito lógico, e trata, especificamente, do conceito de vida do espírito 'Leben des Geistes' (HEGEL, 1993, II, p. 471) ${ }^{1}$, para acentuar o quanto o espírito se distancia da vida, seja da 
dimensão especulativa da vida lógica, quanto da dimensão real da vida natural.

A Ciência da Lógica compõem-se de duas partes: a primeira é a Lógica Objetiva (Doutrina do Ser e Doutrina da Essência) que Hegel define como uma ontologia (Cf. HEGEL, 1993, I, p. 61), uma totalidade cujo objeto é o absoluto; a segunda é a Lógica Subjetiva (Doutrina do Conceito) que trata dos materiais "ossificados" (Cf. HEGEL, 1993, II, p. 243) da lógica tradicional, dividindo-se em: Subjetividade, Objetividade e Idéia. Na parte final da Doutrina do Conceito, Hegel trata da Idéia, cujo modo de ser imediato é a categoria de vida lógica. De início, ele nos adverte que "é necessário observar em que medida a contemplação lógica da vida difere da outra contemplação dela que é científica" (HEGEL, 1993, II, p. 470). Na Lógica, trata-se apenas 'da vida como idéia pura', como uma categoria especulativa e, por isso, ela deve ser diferenciada tanto da vida natural, tal como ela é estudada pela Filosofia da Natureza, quanto da vida em vinculação com o Espírito. Na natureza, a vida é o acabamento, o grau mais elevado que a exterioridade natural alcança; na Lógica, ela é o primeiro momento da Idéia, o mais abstrato, cujo acabamento é a Idéia Absoluta.

A vida, em sua forma lógica, representa a unidade formal imediata do conceito subjetivo e da objetividade, uma unidade de opostos que pode ser compreendida como a unidade do corpo e da alma, ou da forma e da matéria. A vida lógica advém do processo de desenvolvimento das categorias do Ser e da Essência e representa o momento em que o ser é reposto na forma conceitual como idéia imediata, o que nos permite falar de uma ontologia da vida na Ciência da Lógica. Contudo, não vamos desenvolver uma argumentação neste sentido, mas, tão somente, assumir a posição expressa por Marcuse em sua obra: A ontologia de Hegel e a teoria da historicidade ${ }^{2}$, na qual ele analisa a Lógica a partir do conceito de ser que ganha a dimensão real da vida em seu acontecer no tempo.

Neste sentido, Marcuse considera fundamental resgatar o ser como vida e compreendê-lo a partir de sua mobilidade 
histórica, ou seja, a partir do modo como ele acontece no tempo. O ser não se coloca como uma categoria metafísica descolada da realidade, mas ele é a vida que se desenvolve em seu devir. Deste modo, podemos entender porque Marcuse toma o conceito de vida como o cerne da ontologia hegeliana: a vida é o ser acontecendo, e a vida que se constrói de modo histórico é a vida humana, por isso o homem é o centro desta ontologia e, para ser diferenciado de outras formas de vida, o homem deve ser entendido como espírito.

A concepção do sentido ontológico da vida humana como historicidade e sua definição como <<Espírito〉> estão intimamente ligados a um tipo de fundamento filosófico que destaca o sentido do Ser a partir da <<Idéia da vida〉> e põe o devir do ser em geral como mobilidade <<viva〉>; a mobilidade da vida humana sendo apenas um modo privilegiado deste devir. (MARCUSE: 1991, p. 15)

Na Ciência da Lógica, a Idéia é uma unidade, cuja forma inicial é a vida. O conceito ontológico de vida unifica toda dualidade em um ser original, cuja realidade é sempre a unidade de opostos desde sempre postos. A vida lógica é apenas o momento inicial da idéia, a unidade imediata do absoluto, mas em relação a tudo o que lhe antecede, que vem a ser tanto a Lógica Subjetiva quanto as duas partes da Lógica Objetiva, ela é o momento mais completo e, como unidade da subjetividade e da objetividade, ela é, também, o primeiro momento verdadeiramente concreto. Mas, visto que o absoluto não pode ser apenas uma identidade imediata, o processo de desenvolvimento da idéia tem que pôr a complexidade das estruturas conceituais, para alcançar a idéia absoluta que é um resultado, mas que, ao mesmo tempo, é o fundamento das categorias lógicas e das categorias da filosofia do real. A vida lógica, como idéia imediata é, imediatamente, essa unidade categorial da lógica e do real. 
Por isso, podemos falar em uma ontologia da vida, mesmo deixando de lado o conceito de historicidade de Marcuse, pois, dentro dos limites da Lógica, a vida engloba uma totalidade originária, na medida que o ser inicial reaparece pleno como idéia imediata. Se o conceito é a verdade do ser, a idéia é a verdade do conceito e, por isso, ela é o momento mais elaborado do ser, e Hegel chama este momento de vida. A vida lógica, como completude do ser, reúne a totalidade que a antecede e ganha existência na forma de uma efetividade posta pela estrutura conceitual. Com este conceito, Hegel unifica não apenas os princípios filosóficos da modernidade, como também a filosofia antiga e a filosofia transcendental ${ }^{3}$. A ontologia da vida tem sua expressão concreta no espírito, ou seja, no homem capaz de conhecer e de assumir responsabilidades. As demais esferas da idéia referem-se ao avançar da vida por sobre a natureza e o homem primitivo e redundam na esfera do sujeito consciente da sua situação e do seu saber.

\section{A GÊNese Lógica do Espírito}

A última seção da Ciência da Lógica é a Idéia, que é composta de três partes: A Vida, A Idéia do Conhecer e A Idéia Absoluta. O primeiro momento da Idéia é A Vida, também dividida em três partes: $\mathrm{O}$ Indivíduo Vivo, $\mathrm{O}$ processo Vital e o Gênero. O Gênero advém do Processo Vital como o momento da transformação da produção em reprodução. No Indivíduo Vivo a reprodução significa a manutenção de si, o crescimento e a regeneração das partes danificadas; no processo do gênero, a reprodução significa a produção de um outro indivíduo idêntico ao produtor, "no qual o ser-vivo se põe para si idêntico consigo” (HEGEL, 1993, II p. 483). No Processo Vital, o singular relaciona-se com a natureza exterior por impulso de auto-conservação e, deste modo, mantém-se em sua subjetividade; porém, na passagem para o Gênero, a satisfação de suas 
carências não é apenas a manutenção da sua singularidade, mas, principalmente, a posição da universalidade ${ }^{4}$. Todavia, como seu produto é sempre a vida individual, ele permanece preso a imediatez da vida e "não chega a ser para si em seu gênero, porém sucumbe ao poder deste” (HEGEL, E I § 221 Z, 1995, p. 376) ${ }^{5}$.

Cabe assinalar que aquilo que Hegel denomina "gênero" (Gattung) ${ }^{6}$, refere-se ao aspecto biológico de classificação dos seres vivos e não ao gênero (masculino e feminino) dos indivíduos de cada espécie. Não obstante, a reprodução e a perpetuação das espécies é tributária do gênero no sentido sexual. Temos, portanto, no ponto culminante da vida, a diferenciação dos indivíduos iguais e diferentes que se unem para manter a universalidade da qual eles fazem parte como particulares. Deste modo, o Gattung aborda o momento da insuficiência do indivíduo, visto que ele não permanece como indivíduo, mas está fadado ao perecimento, e demonstra também a continuidade do mesmo no outro, visto que ele se une para constituir a universalidade concreta da espécie que só existe nos singulares que, por sua vez, estão em constante devir.

Desde o início, o processo do gênero desvela o conceito em sua unidade diferenciada e compreende um movimento de duplicação que, por sua vez, também é duplo. Em primeiro lugar, o gênero é o universal abstrato que somente existe via a mediação do particular, através da singularidade dos indivíduos vivos, como a forma universal presente em cada membro da espécie. Em segundo lugar, os singulares se duplicam em particulares opostos e complementares, que aparece na diferença de sexos. Este processo é uma referência do vivo a si mesmo por intermédio do outro, de modo a produzir, concretamente, a universalidade da espécie. A reprodução é a finalidade dos organismos vivos e o coroamento da produção de si mesmo em um novo ser independente; este novo ser, embora seja oposto àqueles que o produziram, tem a sua unidade interior no gênero ao qual ele pertence e que é transmitido pelos seus genitores. 
Neste sentido, como o gênero é o universal da vida que só existe no singular, o indivíduo percebe-se no outro igual a si mesmo, mas, independente, este sentimento é a contradição e o impulso em direção ao outro, pois o indivíduo somente-se percebe em sua alteridade. "A relação do gênero é a identidade do sentimento de si (Selbstgefühl) individual em alguma coisa tal que é ao mesmo tempo um outro indivíduo autônomo" (HEGEL, 1993, II, p. 485). Por isso Hegel afirma que o indivíduo é, em si, o gênero, mas não para si, pois para ele existe apenas outro indivíduo que lhe é diferente (cf. Idem, ibid.). Com efeito, como ele tem a forma que lhe é intrínseca, ele a transmite a sua geração e, assim, é o gênero em si; mas ao escolher o outro para reproduzir-se, ele cumpre o impulso da natureza de garantir a universalidade da forma na singularidade de cada nascimento. Com isso, temos a universalidade do gênero se atualizando perpetuamente no singular, como a realidade do conceito que tem a forma da objetividade imediata. Hegel afirma que o conceito efetivo é o germe (Keim) de um indivíduo vivo (Idem, ibid.), no qual se articula sua origem e sua relação ao outro.

Conforme a exposição sistemática da Ciência da Lógica, com a passagem da vida lógica à Idéia do Conhecer, segundo momento da idéia, temos o processo de surgimento do espírito na lógica. A gênese lógica do espírito mostra a prevalência do gênero sobre a individualidade singular perecível. "[..] a idéia da vida se libertou [...] e entra assim na existência como gênero livre para si mesmo. A morte da vitalidade singular somente imediata é o emergir do espírito" (HEGEL, E I, § 222, 1995, p. 377). A Idéia do conhecer representa o advento do espírito lógico porque ele não é mais tributário da imediatez da vida para produzir os seus fins. No gênero, a idéia aparece em sua universalidade abstrata e, como tal, é dependente da realização da sua forma nos indivíduos singulares. $O$ 'gênero livre para si mesmo' é já o espírito lógico que não está mais preso à repetição da vida, contudo, ele tem que engendrar a partir de 
si as suas diferenciações. Este processo ocorre por intermédio da suspensão do movimento da vida, pois esta permanece com as suas características específicas, mas além da permanência da universalidade da espécie, o espírito, como conhecimento e vontade, instaura a possibilidade da permanência da individualidade do vivo com a consciência e a práxis humana que se traduz no conhecimento e nos feitos. $\mathrm{O}$ processo do conhecer está dividido em teoria e prática, ambos como modos finitos de compreensão e ações humanas, pois a verdade infinita de ambos só pode realizar-se na idéia absoluta, que é o modo de unificar a teoria e a prática, ou seja, o conhecimento e o bem humanos em uma unidade intrínseca e não como atividades separadas e intransponíveis entre si. Hegel considera que a prática é superior à teoria, pois ela constrói a sua verdade no mundo, ela instaura o mundo que a teoria, posteriormente, irá interpretar a partir da compreensão teórica da realidade. Por sua vez, esta reflexão acerca dos fatos, que compreende as ciências, as artes e a filosofia, também irá influenciar as ações, portanto, é somente na unidade de ambas que conseguiremos exercer a verdadeira atividade do espírito, que é infinito em si e por si mesmo.

\section{A VIDA DO EsPíRITO}

O organismo vivo é o ponto mais alto a que chega a natureza em virtude de sua complexidade e perfeição, no entanto, ele frui de uma liberdade apenas negativa, porque os indivíduos singulares são sempre uma realização imperfeita da forma e por isso necessitam da reprodução como único meio de manter-se na universalidade. Com efeito, como Kant já observara na Crítica da Faculdade do Juizo (Cf. KANT, KU § 65, 1997, p. 319-324), a vida na natureza funciona como um fim em si e por si mesmo, um sistema que se regula autonomamente, ao contrário das máquinas que necessitam de quem as produza e 
corrija os eventuais problemas de funcionamento. Neste sentido, a natureza está livre da coação exterior, contudo, ela existe apenas como este momento da repetição infinita da própria individualidade, pois os singulares existem apenas para manter a universalidade da espécie em sua existência. A eternidade na natureza, deste modo, é garantida pela repetição exaustiva do mesmo no outro.

O espírito, pelo contrário, dispõe da liberdade positiva, o que lhe permite aceitar a repetição mecânica de si mesmo enquanto indivíduo natural e ao mesmo tempo ultrapassá-la, porque frui da liberdade em sua universalidade e, desta forma, é capaz de traduzi-la no operar técnico de transformação da natureza, mas, sobretudo, na práxis político/ética. Por isso a vida espiritual é o âmbito específico de desenvolvimento da liberdade, pois o homem é capaz de usar a natureza e transformá-la em seu próprio benefício, bem como é capaz de usar o seu próprio corpo como meio de uma atividade espiritual, como escrever um texto, pintar um quadro, cantar uma melodia, proferir uma prece, escrever tragédias ou livros de filosofia, etc.

Contudo, todas estas atividades que denotam a liberdade do espírito não ocorrem nem na mera natureza e nem tampouco em algum lugar etéreo e deslocado da realidade. Toda a atividade humana, como expressão da liberdade da vida do espírito, ocorre no mundo, como um lugar transformado culturalmente pelos homens. Nossas casas, estradas, carros, barcos, aviões, a luz que tenho em casa, a água na torneira, tudo isso é fruto da técnica que os homens criam para poder viver, como se fosse a sua segunda pele. Todo este mundo que nos circunda e ao qual pertencemos, mesmo sem perceber, é a esfera do espírito objetivo que tem a sua realização plena por intermédio dos Estados políticos. Os Estados são como que a casa do homem, ou a casa do espírito, pois sem eles os homens seriam incapazes de viver. 
O Estado é o espírito que fica (steht) no mundo e que se realiza nele como consciência, enquanto que na natureza o espírito só se realiza efetivamente como o outro de si mesmo, como espírito adormecido (HEGEL, FD § 258 Z, 1995, p. 403)?

Com isso, podemos entender porque Hegel afirma que "o Estado é a realidade efetiva da idéia ética" (HEGEL, FD § 257, 1995, p. 398) o reino da liberdade efetivamente realizada, pois o Estado não existe na natureza, mas é fruto da criação humana como o meio-ambiente do homem.

Com efeito, o mundo da cultura é a marca da realização do mundo humano, e esta é a verdadeira natureza do homem, uma natureza não natural, ou não apenas natural. $\bigcirc$ mundo do espírito - que compreende a organização familiar, social, ética, política, religiosa, artística e filosófica - é um mundo necessário, visto que não somos capazes de seguir nossos instintos como os animais, e temos que criar as nossas próprias regras de convivência como uma segunda natureza. Todavia, a sua necessidade está aberta ao desconhecido, e a sua realização, acontece por intermédio das ações de cada indivíduo que são co-responsáveis e co-autores do mundo da cultura, o mundo em que vivemos. Portanto, a vida do espírito compreende tanto a esfera teórica quanto a esfera prática, tanto o aspecto cognitivo quanto os aspectos técnicos e éticos, com as diferenças específicas de cada um, mas também com a inter-relação intrínseca entre eles, pois pensamento, ação moral e ação produtiva são frutos dos mesmos indivíduos e não habitam territórios separados e intransponíveis entre si.

O espírito é o pensamento em geral, e o homem se distingue do animal pelo pensamento. Mas não é preciso imaginar que o homem é, de um lado, um ser que pensa, e de outro, um ser que quer; que em um de seus bolsos ele tem o pensamento e em outro a vontade. Isto seria uma representação vazia. A diferença entre pensamento e vontade é, apenas, a diferença entre a atitude teórica e a atitude prática. Mas não se trata de duas 
faculdades diferentes, pois a vontade é uma forma particular de pensamento: o pensamento que se traduz na existência empírica, o pensamento com propensão a se dar uma existência empírica. (HEGEL, FD § 4 Z, 1995, p. 46-47)

\section{4. À Guisa de Conclusão}

\section{A Vida do Espírito como Reino da Práxis}

O homem é um animal que desconhece a sua situação no universo e sofre por tal desconhecimento. Por um lado, ele não tem a eternidade divina e, por ter necessidades e carências é finito como qualquer outro animal; por outro lado, ele instaura a sua marca no mundo de forma permanente e diferenciada e tem consciência da sua situação singular e de sua finitude. Portanto, o lugar do humano é ambíguo: nem é o espaço da divindade, nem é o espaço da simples natureza, mas está situado na intermediação destas duas esferas. O lugar do humano, por excelência, é a esfera do espírito objetivo, cuja forma mais elaborada é o Estado, onde todas as atividades do espírito absoluto acontecem.

A natureza, de fato, é não divina, pois nela o singular, que é o único a existir realmente, é um ser transitório que apenas sobrevive na espécie. Ao seu entorno, todavia, a espécie, que deveria ser o permanente, tem a sua existência somente no transitório, deste modo, a demanda de universalidade na natureza tem como resposta a indefinida recolocação da finitude.

Todavia, não é isto o que ocorre no mundo do espírito: por intermédio das ações humanas, cuja essência é a liberdade, a universalidade pode realizar-se indefinidamente. A autêntica expressão da atividade espiritual é, na sua existência individual, a realização da universalidade que não é mais afetada pela desigualdade da vida natural. Ao contrário do que ocorre na natureza, para o espírito, não cabe apenas a simples repetição 
de si em um outro indivíduo, mas cumpre ser livre pelo universal e de realizá-lo na própria singularidade existente como fim incondicionado.

Como vimos, o espírito é a marca do humano como capacidade de suplantar a mera repetição natural e instaurar o seu mundo, segundo as suas próprias determinações; deste modo, o homem é o criador de sua realidade. Porém, como o homem universal não existe, mas existem apenas seres individuais submetidos ao tempo, a única permanência que lhes é dada cumprir é a realização de grandes feitos ou de grandes obras. Os homens históricos são aqueles que realizam uma nova etapa do desenvolvimento humano e levam com eles todo um povo, mas há também os artistas e os filósofos que realizam obras que permanecem como marcas da humanidade indefinidamente. Como nem todos os homens são filósofos, artistas ou heróis, a vida ética dentro do Estado, que significa o exercício da liberdade para além do mero interesse privado, é a vida comum que humaniza os homens. Para Hegel, o homem é espírito, e viver como homem é viver dentro de um Estado organizado com o exercício pleno dos seus direitos. Por isso, a práxis é um domínio superior à teoria, pois ela faz o mundo, ao passo que a teoria narra o mundo que passou, ou seja, a filosofia é como "a coruja de Minerva que alça vôo somente ao entardecer” (HEGEL, 1995, p. 28).

Abstract: Hegel does not destine any part of its workmanships to deal with the life of the spirit, however, when explaining the terms where the life must be understood in the Science of the Logic, it differentiate the speculative dimension of the natural dimension and spiritual, mentioning themselves, specifically, to the life of the spirit. We intend, so only, to show the origin and the implications of this concept in Hegel, rank that, if the natural life is the point highest the one that arrives the nature, the life spiritual is the destination of the man and the proper land of the development of the freedom.

Key-words: life, spirit, ontologia, logic, idea. 


\section{NOTAS}

1 HEGEL. G.W.F. Wissenschaft der Logik. In: MOLDENHAUER, Eva; MICHEL, Karl Markus (edt.). Werke. Frankfurt a. M: Suhrkamp, 1993. Neste texto a obra, Ciência da Lógica, será citada pelo Tomo correspondente, I, v. 5 e II, v. 6 seguidos da página da edição alemã.

2 MARCUSE, H. L'ontologie de Hegel et la théorie de 1'historicité. Paris: Gallimard, 1991. O título original é: Hegels Ontologie und die Grundlegung einer Theorie der Geschichtlichkeit, publicada em Frankfurt a.M.: Klostermann, 1932. Citaremos conforme a edição francesa.

3 Um elemento fundamental da análise de Marcuse é a sua afirmação de que Hegel oferece uma nova percepção do problema central posto por Descartes e não resolvido por Kant, a dualidade original entre subjetividade e objetividade, cuja preeminência é posta na subjetividade (Cf, op. Cit. p. 18). Ilting também observa que Hegel estabelece "uma arrojada relação entre a metafísica de Aristóteles e a filosofia moderna", salientando que Hegel explica a "forma imanente ou a alma do ser-vivo como o 'Eu Penso' no 'Cogito ergo sun' de Descartes”, como o 'Eu Penso' enquanto "o sujeito ou a autoconsciência do idealismo moderno", ou como "o sujeito da lógica formal". ILTING, K-H. Hegel Philosophie des Organischen, In: Hegel und die Naturwissenschaften. Stuttgart-Bad Cannstatt: frommann-holzboog, 1987, p. 357.

4 Na Fenomenologia, parte IV, "Consciência de si: A verdade da certeza de si mesmo", encontramos um movimento muito semelhante ao da Ciência da Lógica, em que a vida aparece como 'objeto do desejo' (\$175) bem como a referência ao ser-vivo, ao gênero e ao espírito. "A figura diferente, apenas viva, suprassume sem dúvida no processo da vida mesma, sua independência, mas junto com sua diferença cessa de ser o que é. Porém o objeto da consciên- 
cia de si é também independente nessa negatividade de si mesmo e assim é, para si mesmo, gênero, universal fluidez na peculiaridade de sua distinção: é uma consciência de si viva”. HEGEL, G.W.F. Phänomenologie des Geistes. V. 3, Frankfurt a.M.: Suhrkamp, 1993, p. 144. Seguimos a tradução brasileira: HEGEL, G.W.F. Fenomenologia do espírito I. Petrópolis: Vozes, 1992, § 176, p. 125.

5 HEGEL, G.W.F. Enzyklopädie der philosophischen Wissenschaften. In: MOLDENHAUER, Eva; MICHEL, Karl Markus (edt.). Frankfurt a.M.: Suhrkamp, 1992, 1993 e 1995. A obra será citada sucintamente por (E) Enciclopédia, seguido dos numerais romanos I, II, que designam, respectivamente, E I, Lógica; E II, Filosofia da Natureza seguida do número do respectivo parágrafo, quando se tratar do caput, ou ainda, seguido da abreviação 'A', quando se tratar da Anotação (Anmerkung), ou de 'Z' quando se referir ao Adendo (Zusatz).

6 KANT, I. Kritik der Urteislkraft. Frankfurta.M.: Suhrkamp, 1997. Indicaremos esta obra com as iniciais 'KU', seguida do parágrafo correspondente e a página da edição alemã. Kant, na KU, § 64, p. 318 refere-se também ao Gattung, exemplificando com a árvore que produz outras árvores iguais a ela: "Der Baum aber, den er erzeugt, ist von derselben Gattung; und so erzeugt er sich selbst der Gattung nach, ..." A versão brasileira da KU (Crítica da faculdade do juizo) traduz Gattung por espécie. Todavia, na Enciclopédia II, § 368, no item C:c. [. "O gênero e as espécies", Hegel os diferencia como Gattung e Arten, além de tratar dos outros termos de classificação dos Animais.

7 HEGEL, G.W.F. Grundlinien der Philosophie des Rechts, oder Naturrecht und Staatswissenschaft im Grundrisse. In: In: MOLDENHAUER, Eva; MICHEL, Karl Markus (edt.). Werke. v. 7. Frankfurt a.M.: Suhrkamp, 1995. A obra será designada por Filosofia do Direito, e citada com as iniciais 'FD', seguidas do número do respectivo parágrafo, 
quando se tratar do caput, ou ainda, seguida da abreviação 'A' quando se reportar à Anotação, ou 'Z', quando se reportar aos Adendos (Zusats). A indicação da página será conforme a edição alemã.

\section{REFERÊNCIAS}

BOURGEOIS, B. La Pensée Politique de Hegel. Paris: P.U.F., 1969.

HEGEL, G.W.F. Enzyklopädie der philosophischen Wissenschaften. Frankfurt am Main: Suhrkamp, 1995, tomo I, w. 8; 1993, tomo II, w. 9; 1992, tomo III, w. 10.

. Grundlinien der Philosophie des Rechts. Tomo 7. Frankfurt am Main: Suhrkamp, 1995.

. Phänomenologie des Geistes. Tomo 3. Frankfurt am Main: Suhrkamp, 1993.

. Wissenschaft der Logik. Tomo 5 e 6. Frankfurt am Main: Suhrkamp, 1993.

. Enciclopédia das Ciências Filosóficas. Tomo I e II. Trad. Paulo Meneses. São Paulo: Loyola, 1995.

. Fenomenologia do Espírito. Parte I e II. Trad. Paulo Meneses, Petrópolis: Vozes, 1992.

. Linhas Fundamentais da Filosofia do Direito ou Direito Natural e Ciência do Estado em compêndio. Terceira parte: A Eticidade. Segunda Seção: A Sociedade Civil. Tradução e Apresentação, Marcos L. Müller, Campinas: IFCH/UNICAMP, textos Didáticos, N²1, 2a edição, setembro de 2000. 
- Linhas Fundamentais da Filosofia do Direito ou Direito Natural e Ciência do Estado em compêndio. Terceira parte: A Eticidade. Terceira Seção: O Estado. Trad. Marcos L. Müller. Campinas: IFCH/UNICAMP, textos Didáticos, $\mathrm{N}^{\circ}$ 32, maio de 1998.

. Principes de la Philosophie du Droit ou Droit Naturel et Science de l'État en Abrégé. Trad. Robert Derathé. Paris: Vrin, 1986.

. Science de la Logique. Tome I: L'Être. Trad P.J. Labarrière et Gwendoline Jarczyk. Paris: Aubier, 1972

. Science de la Logique. Tome I: La Doctrine de L'Essence. Trad. P.J. Labarrière e Gwendoline Jarczyk. Paris: Aubier, 1976.

. Science de la Logique. Deuxième Tome: La Doctrine du Comcept. Trad. P.J. Labarrière e Gwendoline Jarczyk. Paris: Aubier, 1981.

ILTING, K. H. Hegel Philosophie des Organischen. In: Hegel und die Naturwissenschaften. Stuttgart-Bad Cannstatt: frommann-holzboog, 1987, Bd. 2.

INWOOD, M. Dicionário Hegel. Rio de Janeiro: Jorge Zahar, 1997.

JAESCHKE, W. Hegel: La conciencia de la modernidad. Madrid: Akal, 1998.

KANT, I. Kritik der Urteilskraft. Frankfurt: Suhrkamp, 1997.

- Crítica da faculdade do juízo.Rio de Janeiro: Forense Universitária, 1993. 
MARCUSE, H. L'ontologie de Hegel et la théorie de 1’historicité. Paris: Gallimard, 1991.

SILVA, M.Z.A., Uma idéia de sistema e o lugar da Filosofia do Direito. Revista Philósophos. v. 1, nº 2, p. 65-75, jul./dez. 1996. WEIL, E. Hegel et 1’État. Paris: Vrin, 1981. 